\title{
Impacto do ácido hialurônico na viabilidade das células mesenquimais derivadas do tecido adiposo cultivadas em membrana de colágeno tipo I/III
}

\section{Impact of Hyaluronic Acid on the Viability of \\ Mesenchymal Cells Derived from Adipose Tissue Grown in Collagen Type I/III Membrane}

\author{
Camila Cohen Kaleka ${ }^{10}$ \\ Mário Ferretti ${ }^{5}$ \\ ${ }^{1}$ Departamento de Ortopedia e Traumatologia, Hospital Israelita \\ Albert Einstein, São Paulo, SP, Brasil \\ 2 Ortopedia Multiprofissional, Hospital Israelita Albert Einstein, São \\ Paulo, SP, Brasil \\ ${ }^{3}$ Laboratório StemCorp de Tecnologia em Células-Tronco, São Paulo, \\ SP, Brasil \\ ${ }^{4}$ Departamento de Ortopedia e Traumatologia, Escola Paulista de \\ Medicina, Universidade Federal de São Paulo, São Paulo, SP, Brasil \\ 5 Programa de Pós-graduação em Ciências da Saúde, Hospital Israelita \\ Albert Einstein, São Paulo, SP, Brasil
}

Pedro Debieux ${ }^{10}$ Eliane Antonioli ${ }^{2}$

Eder Zucconi ${ }^{3 \odot}$

Moisés Cohen ${ }^{4,5}$

Endereço para correspondência Camila Cohen Kaleka, MD, PhD, Av. Albert Einstein, 627/701, Bloco A1-sala 306, São Paulo, SP, 05652-900,

Rev Bras Ortop 2022;57(6):1022-1029.
Resumo
Palavras-chave
- cartilagem articular
- células-tronco mesenquimais
- transplante de células-tronco mesenquimais
- ácido hialurônico
Objetivo Avaliar in vitro a viabilidade das células-tronco mesenquimais derivadas do tecido adiposo (AD-CTMs) em diferentes soluções comerciais de ácido hialurônico (AH) antes e após serem semeadas em membrana de colágeno I/III.
Métodos $\mathrm{Na}$ primeira etapa, analisou-se a interação entre AD-CTMs com sete diferentes produtos comerciais de $\mathrm{AH}$, salina tamponada com fosfato (PBS, na sigla em inglês) e soro fetal bovino (SFB), realizada pela contagem das células vivas e mortas após 24, 48 e 72 horas. Foram selecionados cinco produtos com maior número de células vivas e avaliou-se a interação entre o AH com AD-CTMs e a membrana de colágeno tipo I/III pela contagem de células vivas e mortas no mesmo intervalo de tempo (24, 48 e 72 horas).

\footnotetext{
* Trabalho desenvolvido no Hospital Israelita Albert Einstein, São Paulo, SP, Brasil.
}

recebido

24 de Abril de 2021

aceito

08 de Julho de 2021

Publicado on-line

Fevereiro 9, 2022
DOI https://doi.org/ 10.1055/s-0041-1740198. ISSN 0102-3616.

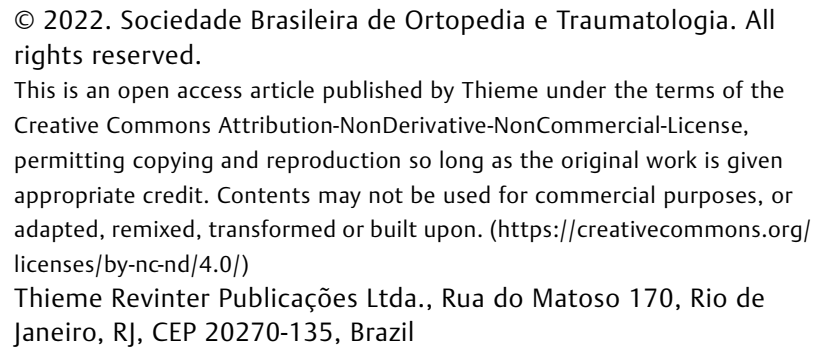

(c) 2022. Sociedade Brasileira de Ortopedia e Traumatologia. All rights reserved.

This is an open access article published by Thieme under the terms of the Creative Commons Attribution-NonDerivative-NonCommercial-License, permitting copying and reproduction so long as the original work is given appropriate credit. Contents may not be used for commercial purposes, or adapted, remixed, transformed or built upon. (https://creativecommons.org/ licenses/by-nc-nd/4.0/) Thieme Revinter Publicações Ltda., Rua do Matoso 170, Rio de Janeiro, RJ, CEP 20270-135, Brazil 
Resultados Em ambas as situações analisadas (AH + AD-CTM e AH+AD-CTM + membrana), o SFB apresentou a maior porcentagem de células vivas após 24,48 e 72 horas, resultado superior ao do $\mathrm{AH}$.

Conclusão A associação do $A H$ com as $A D-C T M s$, com ou sem a membrana, não demonstrou superioridade na viabilidade celular quando comparado com SFB.

\author{
Abstract \\ Keywords \\ - cartilage \\ - articular \\ - mesenchymal stem \\ cells \\ - mesenchymal stem \\ cell transplantation \\ - hyaluronic acid
}

Objective To evaluate in vitro the viability of mesenchymal stem cells derived from adipose tissue (AD-MSCs) in different commercial solutions of hyaluronic acid (HA) before and after being sowed in collagen I/III membrane.

Methods In the first stage, the interaction between AD-MSCs was analyzed with seven different commercial products of HA, phosphate buffered saline (PBS), and bovine fetal serum (BFS), performed by counting living and dead cells after 24,48 and 72 hours. Five products with a higher number of living cells were selected and the interaction between HA with AD-MSCs and type I/III collagen membrane was evaluated by counting living and dead cells in the same time interval (24, 48 and 72 hours).

Results In both situations analyzed (HA + AD-MSCs and HA + AD-MSCs + membrane), BFS presented the highest percentage of living cells after 24, 48 and 72 hours, a result higher than that of $\mathrm{HA}$.

Conclusion The association of HA with AD-MSCs, with or without membrane, showed no superiority in cell viability when compared with BFS.

\section{Introdução}

O manejo dos defeitos da cartilagem é desafiador devido à capacidade limitada de reparação tecidual. Diversas modalidades de tratamento têm sido realizadas para melhorar a cicatrização e promover regeneração. As aplicações biológicas têm ganhado notoriedade nas últimas décadas, ${ }^{1}$ desde a primeira descrição do tratamento com implante autólogo de condrócitos $^{2}$ na década de 1990 . Anos depois, a técnica de implantação celular foi aprimorada com o uso de estruturas tridimensionais (scaffolds), aperfeiçoando os resultados clínicos relatados com até uma década de seguimento. ${ }^{3}$

As células-tronco mesenquimais (CTMs) foram recentemente propostas como opção potencial para restauração da cartilagem. As CTMs são conhecidas por apresentarem características biológicas únicas, incluindo propriedades imunomoduladoras, anti-inflamatórias e de liberação de citocinas prorregenerativas. $^{4-6}$ Elas podem ser isoladas de vários tecidos do corpo humano, ${ }^{7-9}$ incluindo tecido adiposo (ADCTMs), músculo, osso, sinóvia, polpa dentária e cordão umbilical. ${ }^{10}$ As AD-CTMs são obtidas facilmente, além de apresentarem um perfil proliferativo e uma capacidade in vitro de diferenciação semelhantes às CTMs da medula óssea. ${ }^{11}$ As AD-CTMs são consideradas uma fonte celular ideal pela disponibilidade, propriedade não imunogênica, ação anti-inflamatória, e por não apresentarem relação de efeito entre a idade do doador e a capacidade de proliferação e diferenciação. ${ }^{12} \mathrm{~A}$ fim de aprimorar o reparo da cartilagem, as células podem ser cultivadas in vitro em meios com estímulos exógenos (ácido hialurônico [HA] e fatores de crescimento) e, uma vez que atinjam a concentração desejada, podem ser implantadas em matrizes tridimensionais, como membranas de colágeno.
O protocolo ideal do cultivo de AD-CTMs para aplicação clínica ainda está por ser determinado. O AH tem sido considerado um excelente veículo para a administração de CTMs na reparação tecidual. ${ }^{13}$ Trata-se de um biopolímero formado pelo ácido glucurônico e N-acetilglicosamina. Há, entretanto, diversos produtos de AH disponíveis comercialmente, os quais diferem em fatores como origem (animal ou sintética) e propriedades físico-químicas (concentração, pesos moleculares, viscosidade e elasticidade).

Com o intuito de aprimorar a interação entre os scaffolds e as células e, assim, melhorar o processo de reparo da cartilagem, o presente estudo analisou a interação entre ADCTMs, AH e membrana de colágeno. Há um lapso de informações sobre a resposta das AD-CTMs quando expostas ao $\mathrm{AH}$, assim como se produtos comerciais com características diferentes influenciam na atividade celular. Há poucos relatos da interferência do AH como substrato para as AD-CTMs in vitro prévia ou posteriormente à colocação na membrana biossintética de colágeno tipo I/III.

O presente estudo tem como principais objetivos:

1. Avaliar in vitro a viabilidade das AD-CTMs humanas quando em contato com diferentes formulações comerciais de ácidos hialurônicos;

2. Analisar o uso de ácido hialurônico como veículo das ADCTMs em membrana de colágeno tipo I/III.

\section{Materiais e Métodos}

Para a realização do presente estudo in vitro, foram obtidas cinco amostras de tecido adiposo humano para isolamento de ADCTMs, após assinatura do termo de consentimento livre e esclarecido (TCLE) pelo doador, aprovado pelo Comitê de Ética em Pesquisa (CAAE 60075616.5.0000.0071). Os procedimentos 
relacionados à transferência do material biológico, ao isolamento e à manipulação das células in vitro foram realizados em parceria com a empresa StemCorp Serviços Biomédicos Ltda., licenciada pela Agência Nacional de Vigilância Sanitária (ANVISA) como Centro de Processamento Celular segundo os critérios da Resolução da Diretoria Colegiada n 214.

A coleta de entre 10 e $20 \mathrm{~mL}$ de tecido adiposo da região subcutânea abdominal foi realizada pelo cirurgião plástico, no centro cirúrgico, durante procedimento de lipoaspiração. Após a coleta, as amostras foram transferidas para um frasco estéril contendo $10 \mathrm{~mL}$ de solução salina tamponada com fosfato (PBS, na sigla em inglês) $1 \mathrm{X}$ pH 7,4, 200U/mL de penicilina, 200$\mathrm{ug} / \mathrm{mL}$ de estreptomicina, $0,5 \mathrm{ug} / \mathrm{mL}$ de anfotericina e $50 \mathrm{ug} / \mathrm{mL}$ de gentamicina (Gibco). As amostras foram transferidas para uma caixa térmica com monitoramento de temperatura ( 4 a $8^{\circ}$ C) e transportadas até o laboratório para isolamento celular.

As AD-CTMs foram isoladas utilizando os métodos previamente descritos por Vieira et al. ${ }^{14,15}$ Para o cultivo das células in vitro, foi utilizado o meio de proliferação Dulbecco's Modified Eagle Medium low glucose (DMEM-LG, na sigla em inglês) (Gibco) suplementado com $10 \%$ de soro fetal bovino (SFB), penicilina $100 \mathrm{U} / \mathrm{mL}$, estreptomicina $100 \mathrm{ug} / \mathrm{mL}$ e anfotericina $0,25 \mathrm{ug} / \mathrm{mL}$ (Gibco). As trocas de meio foram realizadas a cada 3 dias. Cada linhagem foi mantida incubada a $37^{\circ} \mathrm{C}$ em uma atmosfera úmida contendo $5 \% \mathrm{CO}_{2}$ até atingirem confluência de $80 \%$. Neste ponto, as células foram passadas para novos frascos de cultivo, na proporção de área 1:3, utilizando o reagente TrypLE (Gibco). Este procedimento foi repetido até atingir quantidades de células suficientes para a realização dos experimentos descritos abaixo.

Para o procedimento de criopreservação, as células foram descoladas dos frascos de cultivo utilizando TrypLE (Gibco), centrifugadas e suspensas em meio de congelamento StemPro (Gibco) contendo 10\% DMSO. O congelamento das células foi realizado gradualmente, em criotubos, e elas foram transferidas posteriormente para um tanque de nitrogênio líquido.

\section{Caracterização das Células Isoladas}

Foram estabelecidos os três critérios da Sociedade Internacional de Terapia Celular para a caracterização de CTMs: 1-aderência a superfície plástica; 2-capacidade de diferenciação in vitro em adipócitos, condrócitos e osteócitos; 3-expressão de marcadores de superfície específicos (imunofenotipagem). ${ }^{16}$

\section{Imunofenotipagem}

Para o teste de imunofenotipagem, as células foram cultivadas até a passagem oito, descoladas dos frascos de cultivo e centrifugadas a $200 \mathrm{~g}$ por 5 minutos em temperatura ambiente. Em seguida, o sobrenadante foi descartado e as células foram homogeneizadas e suspensas em PBS. As células foram, então, marcadas com anticorpos monoclonais: CD29-PerCP-Cy5, CD31-PE, CD45-FITC, CD73-PE, CD90-PE, CD105-PE, HLA-ABC-FITC, HLA-DR-PE (BD Biosciences, Franklin Lakes, NJ, EUA), incubadas em temperatura ambiente e protegidas da luz por 30 minutos. Após este período, as células foram lavadas com PBS, centrifugadas a $500 \mathrm{~g}$ por 5 minutos, ressuspensas em solução tampão e colocadas em um citômetro de fluxo BD FACS Canto II (BD Biosciences, Franklin Lakes, NJ, EUA). Os dados obtidos foram analisados no software FLOWJO (TreeStar, Ashland, OR, EUA).

\section{Ensaio de diferenciação}

A análise do potencial de diferenciação das AD-CTMs foi realizada com meios para diferenciação de adipócitos, condrócitos e osteoblastos. Cada grupo celular foi cultivado na presença do meio específico durante 14 dias. Após este período, as células foram coradas com Oil Red O (adipogênica), Azul de Alcian (condrogênica) ou Alizarina Red S (osteogênica). A capacidade de diferenciação foi avaliada pela coloração.

\section{Ensaio de Viabilidade}

\section{Interação Célula/Ácido Hialurônico}

Linhagens de AD-CTMs, na passagem seis, foram descoladas dos frascos de cultivo utilizando solução de TrypLE (Gibco) e centrifugadas a $300 \mathrm{~g}$ por 5 minutos. Ao final do processo, as células foram contadas na câmara de Neubauer e $3 \times 10^{5}$ células foram separadas e adicionadas em microtubos de $1,5 \mathrm{~mL}$, centrifugadas novamente a $300 \mathrm{~g}$ por 5 minutos e suspensas em $20 \mu$ de cada solução. Foram analisados 9 grupos: 7 produtos de $\mathrm{AH}$ (-Tabela 1), PBS $1 \mathrm{X} \mathrm{pH} \mathrm{7,4}$

Tabela 1 Propriedades físico-químicas dos diferentes ácidos hialurônicos analisados

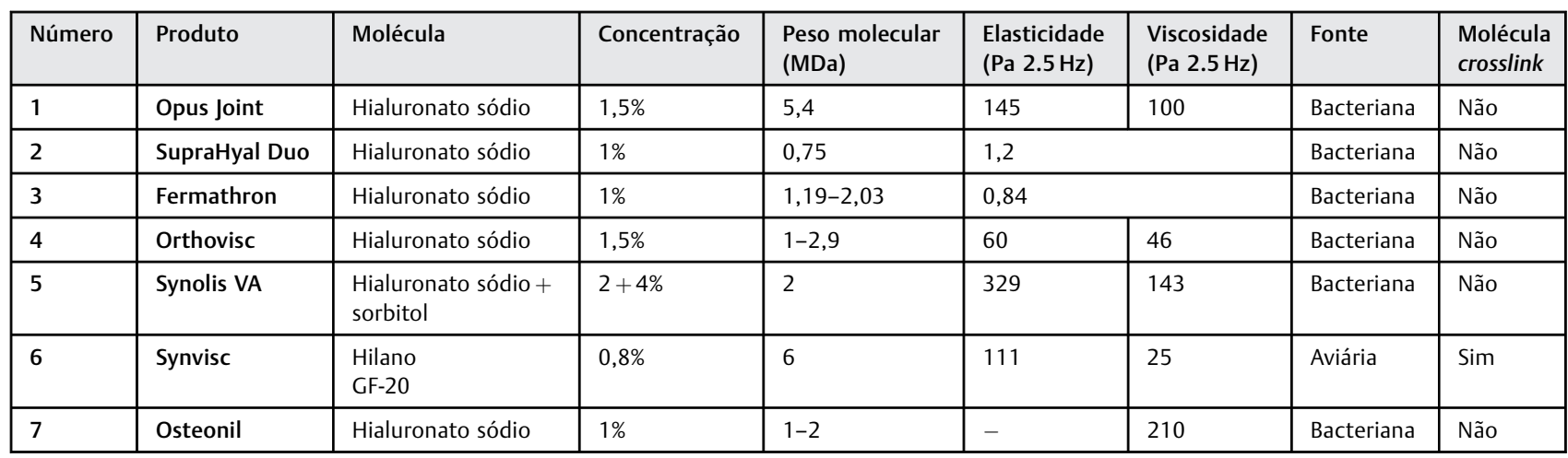

Característica do líquido sinovial:

Elasticidade $=117 \mathrm{~Pa} 2.5 \mathrm{~Hz}$; Viscosidade $=45 \mathrm{~Pa} 2.5 \mathrm{~Hz}$; Peso Molecular $=3-4 \mathrm{MDa} .^{1}$

Fonte: bulas dos produtos 
(controle negativo) e meio de proliferação (SFB). As células foram incubadas com as respectivas soluções por 24,48 e 72 horas em temperatura ambiente.

A viabilidade celular foi estimada pelo número de células vivas pelo kit LIVE/DEAD Viability/Cytotoxicity Assay Kit (Thermo) e o equipamento Countess II FL (Thermo). As imagens das células marcadas, obtidas no Countess, foram contadas com auxílio do software Image J versão 1.8.0_172 (National Institutes of Health, Bethesda, MD, EUA). Toda a parte experimental foi realizada em teste cego e cada produto de $\mathrm{AH}$ recebeu uma numeração. Ao final das análises, os nomes comerciais foram revelados para fins comparativos.

\section{Interação Célula/Ácido Hialurônico/Membrana de Colágeno Tipo I/III}

Para a análise da interação entre AD-CTMs, AH e membrana de colágeno tipo I/III, foram selecionados os cinco ácidos hialurônicos que apresentaram a melhor taxa de viabilidade no experimento anterior.

Linhagens de AD-CTMs, na passagem sete, foram descoladas dos frascos de cultivo utilizando solução de TrypLE (Gibco) e centrifugadas a $300 \mathrm{~g}$ por 5 minutos. Ao final do processo, as células foram contadas na câmara de Neubauer e $2 \times 10^{5}$ células foram adicionadas em microtubos de $1,5 \mathrm{~mL}$, centrifugadas novamente a $300 \mathrm{~g}$ por 5 minutos e suspensas em $40 \mu$ l de produto de $\mathrm{AH}$ (números 1, 2, 4, 5 e 7; - Tabela 1 ), PBS 1X pH 7,4 e SFB. A mistura célula mais solução (AH, PBS, SFB) foi então adicionada na superfície de membrana de colágeno tipo I/III (Chondro-Gide, Geistlich) e acondicionadas em placas de 48 poços. As células foram incubadas por 1 hora em atmosfera de $5 \% \mathrm{CO}_{2}$ a $37^{\circ} \mathrm{C}$, o tempo de adesão das células na membrana, quando, então, foram adicionados 400uL de meio de proliferação. As células foram mantidas na mesma atmosfera por 24, 48 e 72 horas, com análise de viabilidade nestes períodos, utilizando a metodologia descrita com o kit LIVE/DEAD (Thermo).

\section{Resultados}

\section{Isolamento das AD-CTMs do Tecido Adiposo}

Das cinco amostras de tecido adiposo, houve 100\% de sucesso na obtenção de células aderentes para a realização do estudo in vitro. A quantidade coletada para o isolamento das células de cada paciente foram: A1 (11,27g); A2 (18,57g); A3 $(12,16 \mathrm{~g}) ; \mathrm{A} 4(20,99 \mathrm{~g}) ; \mathrm{A} 5$ (18,88g). As amostras foram obtidas de pacientes do sexo feminino com uma média de idade de 30,2 anos. Todas as linhagens apresentaram morfologia compatível às células mesenquimais (longas e fusiformes, semelhantes a fibroblastos), com taxa de proliferação esperada até as passagens avaliadas.

\section{Caracterização das Células Isoladas}

Imunofenotipagem

As cinco linhagens apresentaram características específicas de células-tronco mesenquimais. Observamos porcentual positivo (> 80\%) para os marcadores relacionados à aderência CD29 e CD90; relacionados à caracterização de células

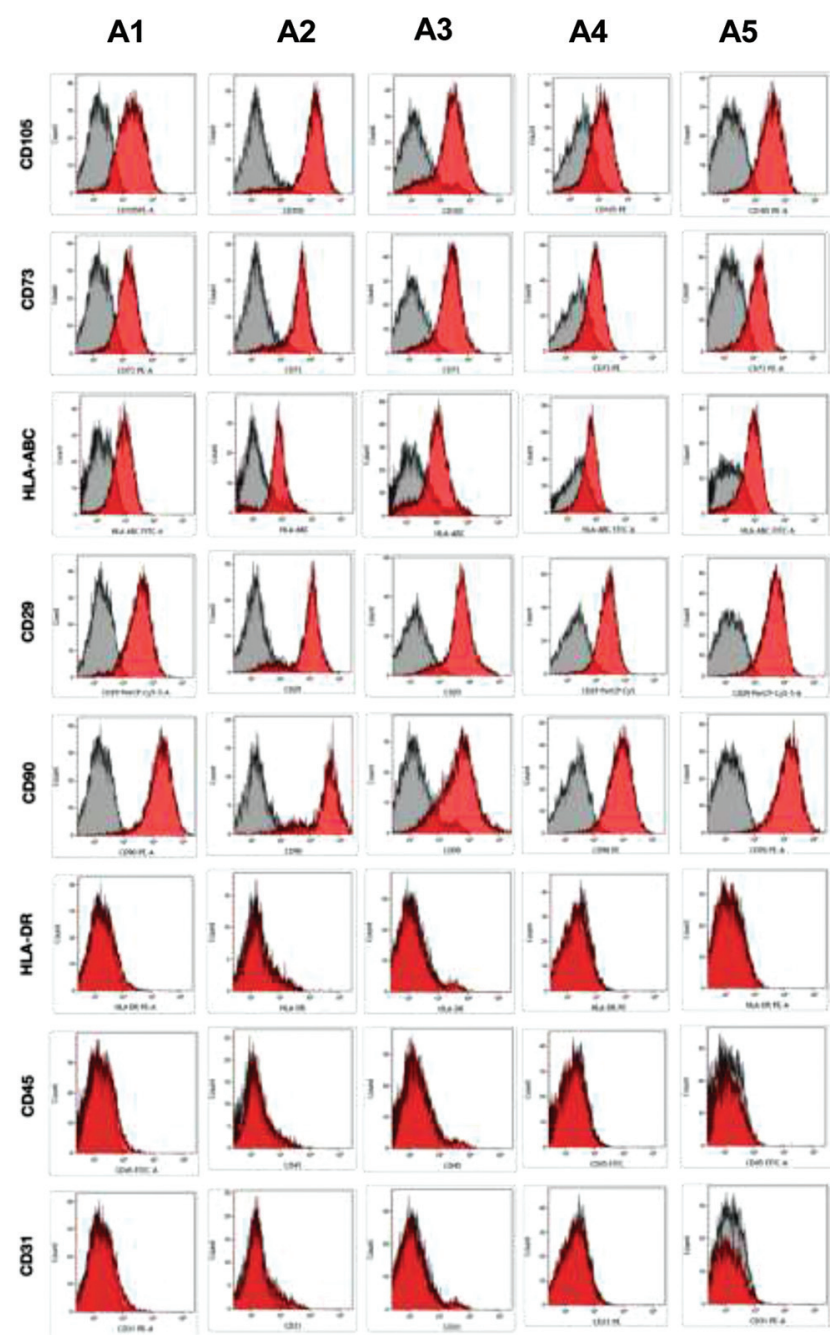

Fig. 1 Imunofenotipagem das células aderentes obtidas do tecido adiposo. Os histogramas em cinza representam a população de células não marcadas com anticorpos (controle negativo). Os histogramas em vermelho representam a população de células marcadas com os respectivos anticorpos descritos em cada linha. Os gráficos mostram o número de células versus intensidade de fluorescência nos cinco casos.

mesenquimais CD73 e CD105; e marcador de MHC classe I HLA-ABC. Observamos porcentual negativo $(<1 \%)$ para 0 marcador hematopoiético CD45; o marcador endotelial CD31; e o marcador de MHC classe II HLA-DR (- Figura 1).

\section{Ensaios de Viabilidade}

\section{Interação Célula com Ácido Hialurônico}

Observamos que o PBS apresentou a melhor taxa de viabilidade nos tempos analisados, sendo, então, considerado a solução de referência para comparações com as demais soluções (-Tabela 2). No momento 24 horas, o ácido 5 apresentou um valor médio de porcentagens de células vivas $(96,2 \% \pm 1,7)$ semelhante à taxa observada com o PBS. Não observamos evidências de diferenças entre o PBS e o ácido 1 ( $p=0,075)$, o ácido 2 ( $p=0,169)$, o ácido 3 ( $p=0,090)$, o ácido $5(p=0,704)$ e o ácido $6(p=0,084)$. No momento 48 horas, $o$ tratamento com ácido 5 também apresentou taxas 
Tabela 2 Valores médios estimados e comparações para as médias e desvios-padrão de porcentagens de células vivas

\begin{tabular}{|c|c|c|c|c|c|}
\hline \multirow[t]{2}{*}{ Momento } & \multirow[t]{2}{*}{ Tratamento } & \multicolumn{2}{|c|}{ Média de \% de células vivas } & \multicolumn{2}{|c|}{ DP de \% de células vivas } \\
\hline & & Média (IC95\%) & valor-p & Média (IC95\%) & valor-p \\
\hline \multirow[t]{9}{*}{$24 h$} & $\mathrm{AH} 1$ & $93,7(90,3-97,3)$ & 0,075 & $2,7(1,4-5,3)$ & 0,956 \\
\hline & $\mathrm{AH} 2$ & $94,4(91,5-97,5)$ & 0,169 & $2,9(1,4-6,0)$ & 0,839 \\
\hline & $\mathrm{AH} 3$ & $93,4(91,4-95,4)$ & 0,090 & $2,1(1,0-4,2)$ & 0,707 \\
\hline & $\mathrm{AH} 4$ & $92,9(88,4-97,6)$ & $<0,001$ & $3,7(2,1-6,5)$ & 0,470 \\
\hline & $\mathrm{AH} 5$ & $96,2(93,3-99,3)$ & 0,704 & $1,7(0,8-3,5)$ & 0,669 \\
\hline & $\mathrm{AH} 6$ & $95,3(91,0-99,8)$ & 0,084 & $2,2(1,0-5,1)$ & 0,854 \\
\hline & $\mathrm{AH} 7$ & $94,7(92,2-97,4)$ & 0,041 & $2,5(1,1-5,6)$ & 0,908 \\
\hline & Meio & $88,2(84,1-92,5)$ & $<0,001$ & $3,8(2,2-6,5)$ & 0,276 \\
\hline & PBS & $97,3(93,2-100,0)$ & Referência & $2,6(0,6-11,4)$ & Referência \\
\hline \multirow[t]{9}{*}{$48 h$} & $\mathrm{AH} 1$ & $95,7(91,7-99,9)$ & 0,097 & $2,4(0,7-7,5)$ & 0,095 \\
\hline & $\mathrm{AH} 2$ & $94,5(91,2-97,8)$ & 0,001 & $1,2(0,8-1,9)$ & 0,865 \\
\hline & $\mathrm{AH} 3$ & $94,1(91,6-96,6)$ & $<0,001$ & $2,6(1,7-4,0)$ & 0,272 \\
\hline & $\mathrm{AH} 4$ & $95,0(90,6-99,7)$ & 0,059 & $3,0(1,6-5,5)$ & $<0,001$ \\
\hline & $\mathrm{AH} 5$ & $95,8(93,4-98,3)$ & 0,089 & $2,8(1,5-5,3)$ & $<0,001$ \\
\hline & $\mathrm{AH} 6$ & $93,5(88,7-98,5)$ & 0,003 & $3,4(1,7-6,7)$ & $<0,001$ \\
\hline & $\mathrm{AH} 7$ & $92,7(87,1-98,6)$ & 0,011 & $2,3(1,8-2,9)$ & 0,173 \\
\hline & Meio & $86,1(81,9-90,4)$ & $<0,001$ & $5,7(2,8-11,5)$ & 0,002 \\
\hline & PBS & $98,1(96,2-100,0)$ & Referência & $1,3(0,4-4,6)$ & Referência \\
\hline \multirow[t]{9}{*}{$72 h$} & $\mathrm{AH} 1$ & $93,9(88,5-99,8)$ & 0,049 & $3,2(1,3-8,2)$ & 0,105 \\
\hline & $\mathrm{AH} 2$ & $94,3(91,8-96,8)$ & $<0,001$ & $3,7(2,4-5,8)$ & 0,308 \\
\hline & $\mathrm{AH} 3$ & $93,6(91,7-95,4)$ & $<0,001$ & $5,6(2,6-12,4)$ & 0,123 \\
\hline & $\mathrm{AH} 4$ & $91,6(86,7-96,8)$ & 0,002 & $3,1(1,5-6,3)$ & 0,299 \\
\hline & AH 5 & $88,5(80,3-97,5)$ & 0,007 & $7,3(3,4-15,6)$ & 0,025 \\
\hline & AH 6 & $93,3(89,4-97,3)$ & 0,002 & $4,6(2,5-8,4)$ & 0,059 \\
\hline & $\mathrm{AH} 7$ & $92,7(90,0-95,4)$ & $<0,001$ & $2,9(2,3-3,7)$ & 0,534 \\
\hline & Meio & $82,6(70,3-97,2)$ & 0,009 & $4,4(2,7-7,2)$ & 0,091 \\
\hline & PBS & $98,6(97,2-100,0)$ & Referência & $2,1(0,6-7,4)$ & Referência \\
\hline
\end{tabular}

Abreviações: AH, Ácido Hialurônico; DP, desvio padrão; IC, intervalo de confiança; PBS, salina tamponada com fosfato.

semelhantes às do PBS $(95,8 \% \pm 2,8)$. Porém, não observamos evidências de diferenças entre o PBS e o ácido $1(p=0,097)$, o ácido $4(p=0,059)$ e o ácido $5(p=0,089)$. No momento 72 horas, todos os tratamentos apresentaram taxas menores de células vivas em relação ao PBS.

\section{Interação Célula/Ácido Hialurônico/Membrana de Colágeno (I/III)}

Após a avaliação dos resultados da primeira etapa (interação $\mathrm{AD}-\mathrm{CTMs}+\mathrm{AH}$ ), foram selecionados cinco AHs com melhor taxa de viabilidade, além do meio (SFB) e o PBS, e observamos uma variabilidade no número de células vivas em relação aos diferentes tratamentos e tempos analisados. $O$ tratamento com SFB apresentou melhor estabilidade entre os tempos analisados, com excelentes taxas de células vivas, $>95 \%$. No tempo zero, observamos uma variação na porcentagem de células vivas entre 87 e 99,96\%. Após 24 horas, observamos uma variação entre 41 e 100\%, sendo que os ácidos 5, 2 e 1 apresentaram maior índice de variabilidade (-Figura 2A). Em 48 horas, a porcentagem de células vivas variou entre 65,8 e $100 \%$ e a maior variabilidade ocorreu com os ácidos 4 , 5 e 7 (-Figura 2B). Em 72 horas, a variação de células vivas foi de 60 a $100 \%$, sendo as maiores variabilidades com os ácidos 1 e 5 ( - Figura 2C).

Na análise das médias estimadas de células vivas, o tratamento com SFB apresentou a melhor taxa de células vivas em 24, 48 e 72 horas, sendo significativo em 24 horas (95,8\%) em comparação com o PBS ( - Tabela 3). Em 48 horas, o tratamento com os ácidos 1 e 5 mostraram-se inferiores, com significância estatística (- Tabela 3). Após 72 horas, porém, não observamos diferenças em comparação com o PBS. Ao compararmos todos os tratamentos, nos 3 tempos, observamos que os ácidos 1 e 5 apresentaram inferioridade em relação ao SBF, com relevância estatística (-Tabela 4). 

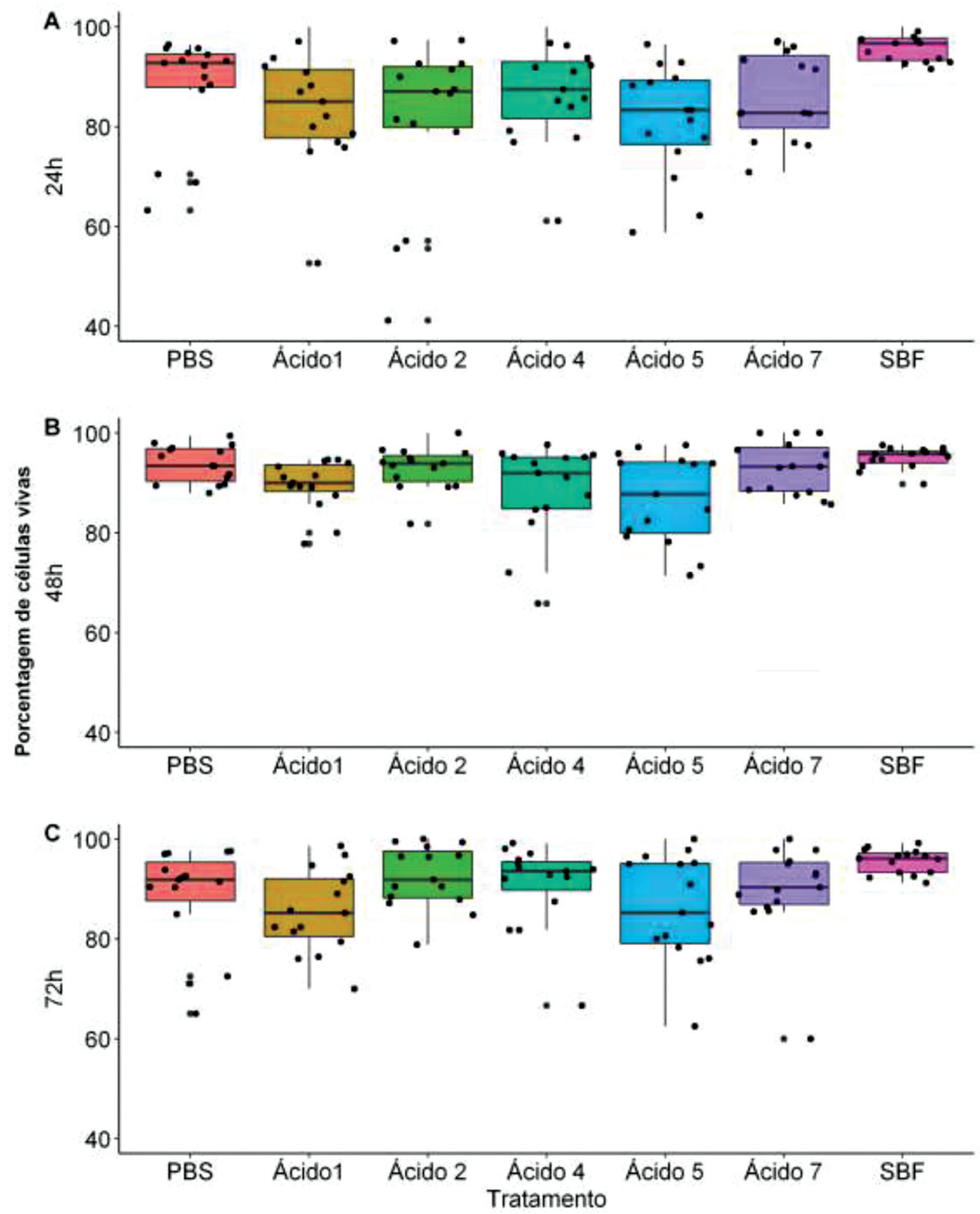

Fig. 2 Porcentagem de células vivas por tratamento em (A) 24 horas, (B) 48 horas e (C) 72 horas.

\section{Discussão}

O presente estudo demonstrou que o ácido hialurônico é um produto biocompatível com as células mesenquimais provenientes do tecido adiposo. Não foi possível estabelecer uma relação entre a viabilidade e o tipo de preparação comercial do produto. A manipulação celular também sofreu interferência de acordo com a viscosidade da formulação. O meio com SFB resultou em uma melhor taxa de viabilidade em todos os tempos analisados (24, 48 e 72 horas), 95\%, superior aos produtos testados. Houve diferença estatística apenas em $24 \mathrm{~h}$ (SBF versus $\mathrm{PBS}$ ) e, neste tempo, os produtos de AH apresentaram desempenho semelhante ao do PBS. Nos demais tempos, considerando o PBS como referência, não houve diferença. 
Tabela 3 Porcentagens de células vivas estimadas em 24, 48 e 72 horas

\begin{tabular}{|c|c|c|c|}
\hline Momento & Tratamento & $\begin{array}{l}\text { Média estimada } \\
\text { (IC95\%) }\end{array}$ & valor-p \\
\hline \multirow[t]{10}{*}{$24 h$} & SFB & $95,8(93,4-97,4)$ & $<0,001$ \\
\hline & Ácido 7 & $86,3(77,7-91,5)$ & 0,826 \\
\hline & Ácido 5 & $81,3(72,3-87,3)$ & 0,350 \\
\hline & Ácido 4 & $86,6(81,8-90,2)$ & 0,801 \\
\hline & Ácido 2 & $81,2(61,8-90,7)$ & 0,429 \\
\hline & Ácido1 & $83,7(74,4-89,6)$ & 0,555 \\
\hline & PBS & $87,8(74,5-94,1)$ & Referência \\
\hline & SBF & $95,0(93,3-96,3)$ & 0,395 \\
\hline & Ácido 7 & $93,0(88,9-95,5)$ & 0,755 \\
\hline & Ácido 5 & $86,9(79,3-91,8)$ & 0,017 \\
\hline \multirow[t]{7}{*}{$48 h$} & Ácido 4 & $88,6(78,6-93,9)$ & 0,222 \\
\hline & Ácido 2 & $92,9(89,8-95,0)$ & 0,699 \\
\hline & Ácido 1 & $89,5(86,7-91,7)$ & 0,033 \\
\hline & PBS & $93,8(90,9-95,7)$ & Referência \\
\hline & SFB & $95,6(93,3-97,0)$ & 0,063 \\
\hline & Ácido 7 & $89,7(84,8-93,0)$ & 0,765 \\
\hline & Ácido 5 & $86,1(78,2-91,1)$ & 0,749 \\
\hline \multirow[t]{4}{*}{$72 h$} & Ácido 4 & $90,8(81,7-95,4)$ & 0,674 \\
\hline & Ácido 2 & $92,5(87,7-95,4)$ & 0,298 \\
\hline & Ácido1 & $85,5(79,7-89,6)$ & 0,671 \\
\hline & PBS & $88,4(75,9-94,4)$ & Referência \\
\hline
\end{tabular}

Abreviações: IC, intervalo de confiança; PBS, salina tamponada com fosfato; SFB, soro fetal bovino.

O AH tem sido amplamente utilizado como biomaterial por suas características de biocompatibilidade e biodegradabilidade. Entretanto, na literatura, há poucos dados quanto ao seu efeito in vitro sobre as CTMs. ${ }^{13,17,18}$ Ding et al. ${ }^{17}$ avaliaram o efeito do AH sobre AD-CTMs provenientes da gordura de Hoffa, concluindo que uma concentração de entre 25 e $75 \%$ de AH não afeta a proliferação celular. Os autores concluíram que a presença de $\mathrm{AH}$ não é tóxica, não alterou a expressão do marcador CD44 (receptor de AH), e tampouco apresentou indução da diferenciação condrogênica das células no curto intervalo de 7 dias, caracterizando o AH como veículo apropriado para injeção das AD-CTMs. ${ }^{17}$

Succar et al. ${ }^{19}$ avaliaram o efeito de diferentes concentrações de AH de alto peso molecular $(0,5 \mathrm{a} 5,0 \mathrm{mg} / \mathrm{mL})$ nas CTMs, mensurando a aderência e a proliferação em superfície plástica e em ensaios de adesão da cartilagem. Uma das hipóteses é que a alta viscosidade influenciaria negativamente a ligação com as células, o que se confirmou ao ser verificado que quanto maior a concentração, menor a aderência, e que o $\mathrm{AH}$ tem efeito dose-dependente na cinética do crescimento celular nas concentrações $>1 \mathrm{mg} / \mathrm{mL} .{ }^{19}$ Durante o nosso estudo, percebemos a interferência negativa da viscosidade elevada na manipulação celular; entretanto, não conseguimos estabelecer relação com a concentração
Tabela 4 Comparações múltiplas entre tratamentos em 24, 48 e 72 horas

\begin{tabular}{|c|c|c|c|c|}
\hline \multirow[t]{2}{*}{ Momento } & \multicolumn{3}{|c|}{ Comparação } & \multirow{2}{*}{$\begin{array}{l}\text { Valor-p corrigido } \\
0,105\end{array}$} \\
\hline & SFB & $x$ & Ácido 7 & \\
\hline & SFB & $x$ & Ácido 5 & 0,003 \\
\hline & SFB & $x$ & Ácido 4 & $<0,001$ \\
\hline & SFB & $x$ & Ácido 2 & 0,497 \\
\hline & SFB & $x$ & Ácido1 & 0,028 \\
\hline & Ácido 7 & $x$ & Ácido 5 & 0,497 \\
\hline \multirow[t]{9}{*}{$24 h$} & Ácido 7 & $x$ & Ácido 4 & $>0,99$ \\
\hline & Ácido 7 & $x$ & Ácido 2 & $>0,99$ \\
\hline & Ácido 7 & $x$ & Ácido1 & $>0,99$ \\
\hline & Ácido 5 & $x$ & Ácido 4 & 0,497 \\
\hline & Ácido 5 & $x$ & Ácido 2 & $>0,99$ \\
\hline & Ácido 5 & $x$ & Ácido1 & $>0,99$ \\
\hline & Ácido 4 & $x$ & Ácido 2 & $>0,99$ \\
\hline & Ácido 4 & $x$ & Ácido1 & $>0,99$ \\
\hline & Ácido 2 & $x$ & Ácido1 & $>0,99$ \\
\hline \multirow[t]{16}{*}{$48 h$} & SFB & $x$ & Ácido 7 & $>0,99$ \\
\hline & SFB & $x$ & Ácido 5 & 0,017 \\
\hline & SFB & $x$ & Ácido 4 & $>0,99$ \\
\hline & SFB & $x$ & Ácido 2 & $>0,99$ \\
\hline & SFB & $x$ & Ácido 1 & 0,033 \\
\hline & Ácido 7 & $x$ & Ácido 5 & 0,197 \\
\hline & Ácido 7 & $x$ & Ácido 4 & $>0,99$ \\
\hline & Ácido 7 & $\bar{x}$ & Ácido 2 & $>0,99$ \\
\hline & Ácido 7 & $x$ & Ácido 1 & $>0,99$ \\
\hline & Ácido 5 & $x$ & Ácido 4 & $>0,99$ \\
\hline & Ácido 5 & $x$ & Ácido 2 & $>0,99$ \\
\hline & Ácido 5 & $x$ & Ácido 1 & $>0,99$ \\
\hline & Ácido 4 & $x$ & Ácido 2 & $>0,99$ \\
\hline & Ácido 4 & $x$ & Ácido 1 & $>0,99$ \\
\hline & Ácido 2 & $x$ & Ácido 1 & 0,204 \\
\hline & SFB & $x$ & Ácido 7 & 0,002 \\
\hline \multirow[t]{14}{*}{$72 h$} & SFB & $x$ & Ácido 5 & 0,012 \\
\hline & SFB & $x$ & Ácido 4 & $>0,99$ \\
\hline & SFB & $x$ & Ácido 2 & $>0,99$ \\
\hline & SFB & $x$ & Ácido1 & $<0,001$ \\
\hline & Ácido 7 & $x$ & Ácido 5 & $>0,99$ \\
\hline & Ácido 7 & $x$ & Ácido 4 & $>0,99$ \\
\hline & Ácido 7 & $x$ & Ácido 2 & $>0,99$ \\
\hline & Ácido 7 & $x$ & Ácido1 & $>0,99$ \\
\hline & Ácido 5 & $x$ & Ácido 4 & $>0,99$ \\
\hline & Ácido 5 & $x$ & Ácido 2 & $>0,99$ \\
\hline & Ácido 5 & $x$ & Ácido1 & $>0,99$ \\
\hline & Ácido 4 & $x$ & Ácido 2 & $>0,99$ \\
\hline & Ácido 4 & $x$ & Ácido1 & $>0,99$ \\
\hline & Ácido 2 & $x$ & Ácido1 & 0,213 \\
\hline
\end{tabular}

Abreviação: SFB, soro fetal bovino. 
dos produtos. Uma limitação é que, nas análises de interação célula $+\mathrm{AH}+$ membrana, não avaliamos os produtos com a menor concentração devido ao resultado insatisfatório observado na viabilidade celular.

Assim, acredita-se que o peso molecular e a viscosidade possam ser os responsáveis pelas diferenças encontradas. Dentre as marcas pesquisadas, o Suprahyal (Meiji Seika, Pharma, Tóquio, Japão) apresentou a maior quantidade de AD-CTMs viáveis no término do período analisado, sendo o produto com o menor peso molecular testado (0,75 MDa). Este resultado pode estar relacionado com a evidência de que AH de alto peso molecular age como inibidor da angiogênese e da proliferação celular, além de ter efeito anti-inflamatório e imunossupressor. ${ }^{6}$ Portanto, pode-se sugerir que a viabilidade celular pode estar diretamente relacionada à concentração e ao peso molecular do AH utilizado e que isto pode ser um fator determinante no sucesso do tratamento da lesão condral. ${ }^{20}$ Deve-se mencionar que os resultados são pertinentes à influência do $\mathrm{AH}$ nas $\mathrm{AD}-\mathrm{CTM}$ no contexto da engenharia tecidual, e não à sua utilização como viscossuplementação no tratamento da osteoartrite.

O presente estudo não está isento de limitações. Trata-se de um estudo laboratorial com resultados experimentais que não devem ser extrapolados para a rotina clínica, embora possam nortear pesquisas futuras. Um número reduzido de amostras foi analisado, apesar do alcance estatístico da amostra.

\section{Conclusões}

O SFB apresentou melhor desempenho para a manutenção da viabilidade das $\mathrm{AD}$-CTMs em comparação com produtos comerciais de $\mathrm{AH}$, sem e com membrana de colágeno. Além disso, o $\mathrm{AH}$ pode ser um meio para a associação de células-tronco mesenquimais do tecido adiposo.

\section{Conflito de Interesses}

Os autores declaram não haver conflito de interesses.

\section{Agradecimentos}

Nosso agradecimento a Mariane Secco (StemCorp) pela assistência no desenvolvimento do presente trabalho.

\section{Referências}

1 Yanke AB, Chubinskaya S. The state of cartilage regeneration: current and future technologies. Curr Rev Musculoskelet Med $2015 ; 8(01): 1-8$

2 Brittberg M, Lindahl A, Nilsson A, Ohlsson C, Isaksson O, Peterson L. Treatment of deep cartilage defects in the knee with autologous chondrocyte transplantation. N Engl J Med 1994;331(14):889-895

3 de Girolamo L, Schönhuber H, Viganò M, Bait C, Quaglia A, Thiebat G, Volpi P. Autologous Matrix-Induced Chondrogenesis (AMIC) and AMIC Enhanced by Autologous Concentrated Bone Marrow Aspirate (BMAC) Allow for Stable Clinical and Functional Improvements at up to 9 Years Follow-Up: Results from a Randomized Controlled Study. J Clin Med 2019;8(03):392
4 Caplan AI, Dennis JE. Mesenchymal stem cells as trophic mediators. J Cell Biochem 2006;98(05):1076-1084

5 Caplan AI. Mesenchymal Stem Cells: Time to Change the Name!. Stem Cells Transl Med 2017;6(06):1445-1451

6 Succar P, Breen EJ, Kuah D, Herbert BR. Alterations in the Secretome of Clinically Relevant Preparations of Adipose-Derived Mesenchymal Stem Cells Cocultured with Hyaluronan. Stem Cells Int 2015;2015:421253

7 Hass R, Kasper C, Böhm S, Jacobs R. Different populations and sources of human mesenchymal stem cells (MSC): A comparison of adult and neonatal tissue-derived MSC. Cell Commun Signal 2011;9:12

8 Astur DC, Lopes JC, Santos MA, Kaleka CC, Amaro JT, Cohen M. Surgical treatment of chondral knee defects using a collagen membrane - autologus matrix-induced chondrogenesis. Rev Bras Ortop 2018;53(06):733-739

9 Harris JD, Brophy RH, Siston RA, Flanigan DC. Treatment of chondral defects in the athlete's knee. Arthroscopy 2010;26 (06):841-852

10 Mohal JS, Tailor HD, Khan WS. Sources of adult mesenchymal stem cells and their applicability for musculoskeletal applications. Curr Stem Cell Res Ther 2012;7(02):103-109

11 Wang YH, Wu JY, Chou PJ, et al. Characterization and evaluation of the differentiation ability of human adipose-derived stem cells growing in scaffold-free suspension culture. Cytotherapy 2014;16 (04):485-495

12 Manferdini C, Maumus M, Gabusi E, et al. Adipose-derived mesenchymal stem cells exert antiinflammatory effects on chondrocytes and synoviocytes from osteoarthritis patients through prostaglandin E2. Arthritis Rheum 2013;65(05):1271-1281

13 Moreno A, Martínez A, Olmedillas S, Bello S, de Miguel F. Hyaluronic acid effect on adipose-derived stem cells. Biological in vitro evaluation. Rev Esp Cir Ortop Traumatol 2015;59(04): 215-221

14 Vieira NM, Zucconi E, Bueno CR Jr, et al. Human multipotent mesenchymal stromal cells from distinct sources show different in vivo potential to differentiate into muscle cells when injected in dystrophic mice. Stem Cell Rev Rep 2010;6(04):560-566

15 Kaleka CC, Zucconi E, Vieira TDS, Secco M, Ferretti M, Cohen M. Evaluation of different commercial hyaluronic acids as a vehicle for injection of human adipose-derived mesenchymal stem cells. Rev Bras Ortop 2018;53(05):557-563

16 Dominici M, Le Blanc K, Mueller I, et al. Minimal criteria for defining multipotent mesenchymal stromal cells. The International Society for Cellular Therapy position statement. Cytotherapy 2006;8(04):315-317

17 Ding DC, Wu KC, Chou HL, Hung WT, Liu HW, Chu TY. Human Infrapatellar Fat Pad-Derived Stromal Cells Have More Potent Differentiation Capacity Than Other Mesenchymal Cells and Can Be Enhanced by Hyaluronan. Cell Transplant 2015;24(07): 1221-1232

18 Lam J, Truong NF, Segura T. Design of cell-matrix interactions in hyaluronic acid hydrogel scaffolds. Acta Biomater 2014;10(04): 1571-1580

19 Succar P, Medynskyj M, Breen EJ, Batterham T, Molloy MP, Herbert BR. Priming Adipose-Derived Mesenchymal Stem Cells with Hyaluronan Alters Growth Kinetics and Increases Attachment to Articular Cartilage. Stem Cells Int 2016;2016:9364213

20 Monaco G, El Haj AJ, Alini M, Stoddart MJ. Sodium Hyaluronate Supplemented Culture Media as a New hMSC Chondrogenic Differentiation Media-Model for in vitro/ex vivo Screening of Potential Cartilage Repair Therapies. Front Bioeng Biotechnol 2020;8:243 